\title{
Interactive comment on "Circulation changes in the Amundsen Basin from 1991 to 2015 revealed from distributions of dissolved ${ }^{230}$ Th" by Ole Valk et al.
}

\section{Anonymous Referee \#2}

Received and published: 16 July 2019

Valk et al provide convincing evidence of decreasing 230Th concentrations in the Amundsen Basin, which they attribute to increased scavenging over Eurasian shelves followed by transport of the water masses to the central Arctic. They use data from three different campaigns to show the 230Th decrease between 2007 and 2015, and they support their explanation for the observed decrease with a model. The study presents important and novel results, but certain points in the text and figures should be clarified and condensed before publication. Specific comments are listed below.

General comments:

- Section 1.3.1: Instead of reviewing the previously published studies chronologically, 
it would be more helpful if similar studies were grouped together (i.e. the Moran 2005 and Hoffmann 2013 studies, which both focused on $231 \mathrm{~Pa} / 230 \mathrm{Th}$ ratios in sediments and came to similar conclusions about $\mathrm{Pa}$ export). This way the focus is on the results and current state of knowledge, instead of on the individual papers.

- Section 3.1: This results section is repetitive and should be condensed. Instead of listing the results by year, similar results could be stated in one sentence (e.g. "The depth profiles of 230Th increased with depth in 1991, 2007, and 2015", or, "Concentrations in the deep Makarov Basin were always higher than those observed in the Amundsen Basin")

- Sections 2.1 and 4.5: The Rutgers van der Loeff (2018) model provides support for the authors' hypothesis that the signal of increased scavenging over the shelves can be transported to the basin and propagated through the deeper parts of the water column. However, more details on the model would be appreciated in section 2.1, specifically regarding the exchange process used to introduce the ventilated water mass. Also, Figure 7 shows that after 8 years the ventilation signal does not reach below $3000 \mathrm{~m}$. Can the authors comment on this difference between the model and data?

- Section 4.6: The first sentence of this section states that the processes affecting 230Th in the Makarov Basin could also provide an explanation for the changes observed in the Amundsen. The first hypothesis suggests that intermediate waters are advected from the Amundsen to the Makarov, and then the 230Th concentrations are reduced by mixing. However, the 230Th concentrations in the Makarov are higher than those in the Amundsen, so it is not clear how mixing with other Makarov basin water masses would reduce concentrations, and it is also not clear how this could provide an explanation for the decrease observed in the Amundsen Basin. Further, this section states that the salinities increased in the Makarov Basin, as opposed to the decrease observed in the Amundsen, which contradicts the first sentence of this section that suggests the changes are occurring through the same mechanism.

Interactive comment
Printer-friendly version

Discussion paper 
- Figures 3 and 8 present the exact same data as figures $2 \mathrm{~A}$ and $2 \mathrm{C}$. I recommend that they be removed from the manuscript.

OSD

- Title and last sentence of abstract: The title and abstract suggest that the 230Th data indicate changes in circulation, but my understanding is that the decrease in 230Th suggests increased scavenging over the shelves, not a change in circulation pathways. The changes in salinity indeed reflect a larger influence of Atlantic water, but the wording of the title suggests that the circulation changes are deduced from Th, not salinity. I suggest the authors consider a rephrasing of the title and/or abstract.

Specific comments:

- Section 1.1 heading: "patters" should be "patterns"

- Page 3, line 23 (Section 1.2): Please cite the reference that states that shelves make up $30 \%$ of the area of the Arctic. I am more familiar with the Jakobsson 2002 study (doi: 10.1029/2001GC000302) that says shelves make up $>50 \%$ of the area.

- Page 4, lines 7-8 (Section 1.3): Add the half-lives of the other Th isotopes here

- Page 5, line 13 (Section 1.4): Rephrase this sentence, as written it suggests that all of these processes are declining instead of changing (". . .ice cover is rapidly declining, as are changes in....")

- Page 7, line 3 (Section 3): Please briefly explain the excess corrections described in Hayes et al 2015, since this correction is important to the results presented here.

- Section 3.2: A sentence should be included to explain the pink 2007 station 400 results if this data is shown on the figure.

- Page 8, lines 4-5 (Section 3.3): I am confused by the last sentence in this section, which compares the Amundsen and Nansen Basins. Because the particulate concentrations are not shown on the figure, please state the range of particulate concentrations in question (for both the Amundsen and Nansen Basins).
Interactive comment
Printer-friendly version

Discussion paper

C3 
- Page 9, line 6: Switch "generally" and "did" so the sentence reads "generally did not" - Page 10: Lines 1-2 and 5-6 are both stating that intermediate waters in the Amundsen OSD had more Atlantic influence in 2015; these two sentences should be combined to avoid repetition.

- Page 10, line 19: Delete "water depth at" so the sentence reads "...concentrations are $8.23 \mathrm{fg} / \mathrm{kg}$ at $1000 \mathrm{~m}$ and ..."

- Page 10, line 25: This sentence references increased inputs of terrestrial matter and increased primary production; what increase is being referred to here? An increase compared to earlier years?

- Page 10, line 27: Are the high concentrations of Fe at the margin or in the basin?

- Page 10, line 28: Instead of saying "... the deep water is in the fluence of BSBW" I suggest saying "deepest water", because the depth of $1200 \mathrm{~m}$ is relatively shallow compared to the other stations.

- Section 4.6: The heading for this section may be missing a word, it does not make sense as written.

- Page 12, line 9: I suggest deleting this sentence and putting the figure references at the end of the first sentence instead.

- Conclusion: I find the conclusion well-written and a good summary of the paper.

Figures:

- Figure 1: Please include stations from the Makarov Basin that are referenced in the study.

- Figure 1: The Gakkel Ridge (GR) is not defined in the caption, and is not visible with the chosen color scale.

- Figure 2: Figures $2 \mathrm{C}$ and $2 \mathrm{~F}$ are from the Makarov Basin while all the other panels 
are from the Amundsen. I suggest making panels $2 \mathrm{C}$ and $2 \mathrm{~F}$ a separate figure, or at least putting them next to each other (by switching panels $2 \mathrm{C}$ and $2 \mathrm{E}$ ).

OSD

- Figure 2: If the stations on Figure $2 \mathrm{E}$ are numbered, there is no need to plot them in different colors. It would be easier to follow if they were all blue (to indicate data from 2015), and the different symbols used to denote the station numbers in panels $A$ and $B$ could be continued in this panel.

- Figure 2: It is confusing that one station from 2007 is plotted in pink and another in green. The pink data were collected close to the margin, while the green station was in the Amundsen Basin. The pink data therefore make it difficult to discern the trend of decreasing Th in the basin that is the focus of the study, and they are also not explained in the caption for panel A. Instead of having two labels that say "2007", I suggest specifying "2007, margin" and "2007, basin" for the pink and green stations, respectively, to make the basin trend more clear.

- Figure 2D: Move the 2015 label beneath the other labels, so it is easier to find.

- Figure 2F: Are the red/orange stations from 2015? The 2015 year label is missing.

- Figure 4: The x-axis should be at the top of the plots, consistent with the other depth profile figures.

- Figure 5: I think a period is missing after the first sentence of the caption (between Amundsen Basin and BSBW)?

- Figure 6: It would be helpful to keep the symbols and colors the same between panels A and $C$.

- Figure 8: The caption is incorrect (should be Makarov Basin not Amundsen Basin).

Interactive comment on Ocean Sci. Discuss., https://doi.org/10.5194/os-2019-49, 2019.
Interactive

comment
Printer-friendly version

Discussion paper 